\title{
A Comparative Study of Language Meta-cognitive Strategies Use between English Major and Non-English Major students
}

\author{
YAN Lu \\ School of foreign studies Jilin Business and Technology College \\ China 130000 \\ E-mail: 154859525@qq.com
}

\begin{abstract}
In the1960s and 1970 s, there was a shift of the foreign language teaching research from "how to teach" to "how to learn". Based on learning strategy theory, this paper makes an analysis of the differences in the adopting of meta-cognitive strategies and the correlations with their academic achievements in English. The findings are as follows: 1) the motivation, metacognition and self-directed learning behaviors of language students are subject to the environment and their backgrounds; 2) the target value and causal attribution, the two factors related to motivation, and metacognition are closely correlated with self-directed learning behaviors;3) resource-based and self-directed learning models can help students improve their self-directed learning behaviors, but the provision of learning resources alone is not enough to improve their self-directed learning ability and outcomes as intervention is also necessary. The teachers through meta-cognitive strategies provide some implications to instruct students and improve teaching quality, and meanwhile, the college students through meta-cognitive strategies improve their English autonomous learning competence, study efficiency and English proficiency.
\end{abstract}

Keywords-meta-cognitive strategies ; English major students; non-English major students; autonomous learning competence

\section{INTRODUCTION}

In recent years, it has become self-evident to view the language learner as an active participant in language learning activities. There are two reasons for shit: the goals of language learning and the perception of language learning have changed. Firstly, society has made a request for education which affects the educational form. Nowadays, communication seems to play a more and more important role in the world. Helping learners to develop the communicative competence has been set as goal of language education and making learners be armed with skills that can help them cope with various challenges globalization brings has been considered a new responsibility of educational institutions. Secondly, research in psychology, cognitive psychology and sociology, linguistics and other fields have increased our understanding of language learning. From the research, we know all the language learners use some kind of learning strategies; however, different learners and under different conditions, the frequency and variety of strategy use vary are different.

The author has investigated language learning strategies use by English major students and non-English major students in Jilin Business and Technology College, which were sampled for three different teaching models. We hope that the study can help English major students and non-English major students through the application of meta-cognitive strategies improving their study efficiency and their English proficiency. By now, many studies on the meta-cognitive strategies have been conducted by college students as a whole, but only few are on comparative studies of meta-cognitive strategies between English major students and non-English major students in Chinese universities. It is on the aspect that we focus on study.

\section{THE RELATIONSHIP BETWEEN STRATEGy USE AND LEARNING PROFICIENCY}

An abundance of research has been conducted to find out whether the frequency of strategy use influence language proficiency, but no consistent picture has emerged. In studies conducted in a variety of geographical and cultural settings, "students who were better in their language performance generally reported higher levels of overall strategy use and frequent use of a greater number of strategy categories" (Green and Oxford, 1995:265).A recent study by Wharton further supports the finding of the study. Wharton examined the self-reported leaning strategy use of 678 university students learning Japanese and French as foreign language in Singapore. There are 80 strategies was investigated and the results showed more learning strategy use among learner with higher proficiency.

While most studies have discovered this linear relationship between learning strategy use and language proficiency, some different results are also apparent in the literature .Abraham and Vann $(1987,1990)$ in two separate studies looked at the language learning strategies employed by both successful and unsuccessful learners. These distinctions were made by measuring the speed with which they moved through a intensive English program. They found that unsuccessful learners were using the strategies generally considered as useful, often the same as those employed by the successful learners. The differences lay in the degree of flexibility the learners showed when choosing strategies, and how appropriately they were applied to the given situation.

Although most findings from the research on LLS might indicate an association between reported strategy use and 
proficiency, the exact nature of this association, particularly the issue of causality, is a subject of some debate. Skehan (1989) and Rees -Miller (1993) among others have pointed out that the existence of correlation between the two does not necessarily suggest causality in a particular direction. Maclntyre (1994) has attempted to reveal the relationship between the two variables. On the one hand, he stresses a need for caution when looking at studies which suggest that more proficient student make better use of strategies: "This might be interpreted to mean that either proficiency influences the choice of strategies or that strategy choice is simply a sign of proficiency level" (p.188). However, in answer to his own question as to whether strategy use results from or leads to increased proficiency, he is rather less cautious: "The answer, undoubtedly, is BOTH" (P. 189). ${ }^{[4]}$

To sum up, the quest for the best LLS for all language learners has ended up showing a picture much more complex than anticipated. Different findings also exist and no pattern has appeared concerning the relationship between specific strategy use and language proficiency.

\section{RESEARCH Methodology}

\section{A. Research Design}

Subjects in this study were127 non-English major and 61English major in Jilin Business and Technology College. To ensure the subjects were basically on the same level before the experiment, three classes (127 students) of non-English majors were sampled for three different teaching models, i.e., resource-based and self-directed listening and reading learning model with intervention (40students), resource-based and self-directed learning model without intervention (42 students), and traditional listening and reading learning model (45 students). As there were only two English-major classes, one was experimented on with the model with intervention (30 students) and the other with the one without intervention (31 students). In the three models, the students used the same textbooks, were lectured by the same teachers, took the same test, and spent the same hours in class (4 hours/week). In the resource-based and self-directed learning model, students finished their listening and reading studies on their own (3 hours/week). Specifically, in the self-directed learning model with intervention, the subjects were intervened with training sessions, including learning strategy training and monthly listening tests; whereas in the model without intervention, the subjects were offered learning resources only and no trainings for the purpose of intervention were scheduled. In the traditional model, the listening courses were lectured by teachers in class ( 2 hours/week) and the reading studies were finished in the form of reading assignments after class set by the teachers for the students who were tested in class.

\section{B. Research instruments}

In this paper, the research instruments include interview, questionnaire, examination to collect and analyze data of questionnaires.SPSS12.0 will be adopted to process and analyze data so as to conduct the correlation of meta-cognitive strategies and English autonomous learning competence.

\section{Interview}

In accordance with the questionnaire results and the subjects' English test results, the author interviewed 22 students with either high, medium or low English proficiency from the surveyed classes in March 2016 and March 2017. The interview was designed as a semi-structured interview centered on the questionnaire.

\section{Test}

Pre-test: based on the results of the English entrance exam designed by the teachers in our college. Mid- and post-tests: the English tests designed by the teachers in our college and taken in March 2016 and March 2017. For non-English majors, the tests were divided into 5 parts: listening, reading, grammar and gap-filling with words, cloze, and writing. The English majors took part in elementary English tests and listening tests. Lest the reliability of the data should be undermined by subjective grading, the listening and reading tests consisted of objective questions and gap-filling only.

TABLE I. SCALE STRUCTURE

\begin{tabular}{|c|c|c|c|}
\hline & Factors & $\begin{array}{c}\text { Number } \\
\text { of } \\
\text { Questions }\end{array}$ & Details \\
\hline \multirow{4}{*}{ Motivation } & Self-determination & 4 & $\begin{array}{l}\text { The desire to determine } \\
\text { their own learning } \\
\text { objectives and subjects, } \\
\text { to assess their } \\
\text { performance and to take } \\
\text { responsibility for their } \\
\text { own studies }\end{array}$ \\
\hline & Self-efficacy & 5 & $\begin{array}{l}\text { Self-assertion, } \\
\text { performance } \\
\text { expectation, target and } \\
\text { positioning, and belief } \\
\text { in learning outcomes }\end{array}$ \\
\hline & Causal attribution & 5 & $\begin{array}{l}\text { Attribution of their } \\
\text { success or failure, as } \\
\text { well as their strategies }\end{array}$ \\
\hline & Target value & 3 & $\begin{array}{l}\text { Integrative motivation } \\
\text { and instrumental } \\
\text { motivation in language } \\
\text { learning }\end{array}$ \\
\hline \multicolumn{2}{|c|}{ Metacognitive strategy } & 8 & $\begin{array}{l}\text { Setting objectives, } \\
\text { making and executing } \\
\text { plans, assessing } \\
\text { performance, and } \\
\text { selecting learning } \\
\text { strategies }\end{array}$ \\
\hline \multirow{2}{*}{$\begin{array}{l}\text { Self-directed } \\
\text { learning } \\
\text { behaviors }\end{array}$} & $\begin{array}{l}\text { Behavioral } \\
\text { dimension } 1\end{array}$ & 8 & $\begin{array}{l}\text { Communication, } \\
\text { writing, cooperation, } \\
\text { clarification, reflection, } \\
\text { etc. }\end{array}$ \\
\hline & $\begin{array}{l}\text { Behavioral } \\
\text { dimension } 2\end{array}$ & 4 & $\begin{array}{l}\text { Note-taking, } \\
\text { information research, } \\
\text { and generic listening } \\
\text { and reading practice }\end{array}$ \\
\hline
\end{tabular}

\section{E. Experimental Procedures}

The study lasted for a year during which the students were surveyed twice with regard to their motivation, meta-cognitive strategies, and learning behaviors and outcomes in their first and third semesters. The statistical results were then analyzed.

\section{1) Results and Analysis}

From Fig. 1, we can see that students in the model with intervention gave remarkably different answers to the second questionnaire from those they gave to the first. Apart from causal attribution, they had a marked advance in all dimensions in the section of motivation, metacognitive ability 
and self-directed learning behaviors. Results of the T-test show that the advance is of great significance $(\mathrm{p} \leq .05)$.

Fig. 2 shows that students in the model without intervention improved themselves in terms of target value, metacognitive ability and self-directed learning behaviors after two semesters but no significant improvement was made in their average self-determination and self-efficacy results. Results of the T-test show that the two sets of data are both of statistical significance $(\mathrm{p} \leq .05)$.

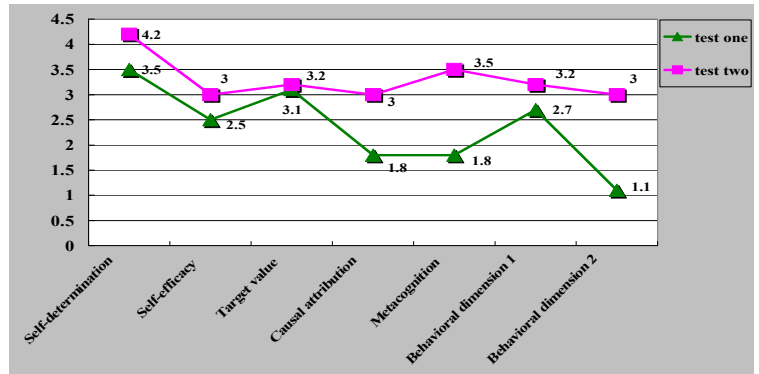

Fig. 1. Descriptive Statistics of the Two Questionnaires on the Model with Intervention

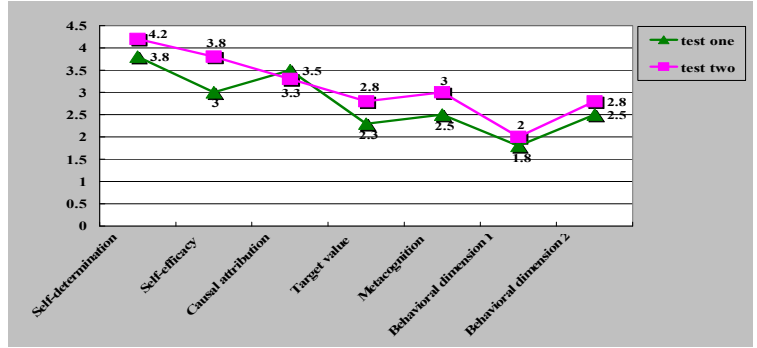

Fig. 2. Descriptive Statistics of the Two Questionnaires on the Model without Intervention



Fig. 3. Descriptive Statistics of the Two Questionnaires in the traditional model

From Fig. 3, we can see that students in the traditional model showed much improved target value, metacognitive ability and self-directed learning behaviors in the second questionnaire over the first, which is of great significance $(p \leq 0.05)$. Thus, it is evident that there have been varying changes in the self-directed learning psychologies and behaviors of the students in the three models after two semesters. Their motivation, metacognitive ability and self-directed learning behaviors were improved to different extent after one year.

2) Comparison of the Motivation, Metacognitive Ability, Self-directed Learning Ability and Learning Outcomes in Different Models

To understand whether the model with intervention is more conducive to the improvement of motivation to learn foreign languages, metacognitive ability, and self-directed learning behaviors than the model without intervention, we compared the three models based on the questionnaires and tests in January, 2017.

The following table shows the T-test and one-way ANOVA results of the three models:

G1, G2 and G3 are respectively comparisons of the listening, reading and total scores in the final test with those in the pre-test. Our study shows that students showed different levels of motivation, metacognition and self-directed learning ability in different models. In all the motivation-related and metacognition-related dimensions, the model with intervention exhibits the most significant advantages, followed by the traditional model. In terms of self-directed learning behaviors, the self-directed learning models, either with or without intervention, are much better than the traditional model.

Table 2 shows that the model with intervention averages higher than the one without intervention in every dimension with the exception of behavioral dimension 1. And the T-test results show that such a difference is of great significance in terms of self-determination, causal attribution, metacognition strategy and behavioral dimension 2. A comparison between the model with intervention and the traditional model reveals that the former averages higher than the latter all the time and that the two show significant differences in causal attribution and self-directed learning behaviors. The model without intervention averages lower than the traditional model in all motivation-related and metacognitive dimensions and particularly lower in self-determination. But it averages higher than the traditional model in the two dimensions of self-directed learning behaviors.

The following figure is the one-way ANOVA results of the three models

TABLE II.

THE ONE-WAY ANOVA RESULTS OF THE THREE MODELS

\begin{tabular}{|c|c|c|c|c|c|c|c|c|c|}
\hline & & \multicolumn{6}{|c|}{ T-test T } & \multirow{2}{*}{\multicolumn{2}{|c|}{$\begin{array}{c}\text { One-way ANOVA } \\
\text { G1-G2-G3 }\end{array}$}} \\
\hline & & \multicolumn{2}{|c|}{ G1-G2 } & \multicolumn{2}{|c|}{ G1-G3 } & \multicolumn{2}{|c|}{ G2-G3 } & & \\
\hline & & t & $\mathbf{P}$ & t & $\mathbf{P}$ & t & $\mathbf{P}$ & $\mathbf{F}$ & $\mathbf{P}$ \\
\hline \multirow{4}{*}{ Motivation } & Self-determination & 3.5 & 0 & 0.52 & 0.61 & -2.9 & 0 & 8.25 & 0 \\
\hline & Self-efficacy & 1.77 & 0.07 & 0.46 & 0.67 & -1.25 & 0.22 & 1.76 & 0.15 \\
\hline & Causal attribution & 3.12 & 0 & 2.65 & 0.02 & -0.32 & 0.76 & 5.89 & 0 \\
\hline & Target value & 1.26 & 0.15 & 1.06 & 0.25 & -0.18 & 0.83 & 0.96 & 0.37 \\
\hline \multicolumn{2}{|c|}{ Metacognition } & 2.01 & 0.03 & 0.38 & 0.66 & -1.64 & 0.08 & 2.55 & 0.06 \\
\hline \multirow{2}{*}{ Self-directed behaviors } & Behavioral dimension 1 & -0.08 & 0.91 & 2.12 & 0.02 & 2.01 & 0.03 & 2.72 & 0.04 \\
\hline & Behavioral dimension 2 & 2.60 & 0.01 & 3.06 & 0 & 0.44 & 0.64 & 5.43 & 0 \\
\hline
\end{tabular}


The one-way ANOVA results of the three models in the pre-test show that there were no significant differences among the subjects in the three models in terms of their English performance prior to the experiment. With a comparison of the test results in January, 2017, we can see that students in the model with intervention had a greater advance in their final English grades and listening and reading scores in the final test than the students in the other two models. Furthermore, the traditional model produced better learning outcomes than the model without intervention. Thus we can see that the learning model with intervention does contribute to stronger motivation to learn foreign languages, higher metacognitive ability, more self-directed learning behaviors and better learning outcomes.

\section{Discussion AND SugGestions}

\section{1) Changes in Motivation, Metacognition and} Self-directed Learning Behaviors

The above survey shows that the students had a marked advance in motivation, metacognitive ability and self-directed learning behaviors in two semesters. The study has also found that they had a better understanding of the purposes and value of learning foreign languages, used the metacognitive strategies more often than before, and significantly improved their self-directed learning behaviors. The changes are possibly related to the change of their learning environment. Rather than solely relying on in-class instruction, foreign language learners have to rely more on themselves to set plans and objectives, assess their learning outcomes, and improve comprehensive English proficiency. In a changed environment, the students can be forced to enhance their understanding of language learning and hone their learning management skills. However, as it can grow harder the more they learn, there will be a growing performance gap among them and more frustrations in their language studies, discouraging some of them from continuing their learning. It's a view supported by the declining causal attribution results of the three models, as well as the interviews

Those results caution us that teachers should make the most of the freshmen's motivation to learn, nurture it and develop their metacognitive ability and self-directed learning ability. Those results caution us that teachers should make the most of the freshmen's motivation to learn, nurture it and develop their metacognitive ability and self-directed learning ability.

2) Changes in Motivation, Metacognition, Self-directed Learning Ability and Learning Outcomes in Different Learning Models

From the above comparative analysis of different models, we can see that the learning model with intervention is much more superior in terms of improving motivation, metacognitive ability, self-directed learning behaviors and learning outcomes. Statistics show that students in different models desired self-determination at all stages, a reflection of their strong sense of autonomy and reluctance to settle for the passive learning model where teachers determine what they learn and how their studies are scheduled. The heart of self-directed learning is to allow the students to play a more active role in their studies and develop their ability to make decisions on learning opportunities and strategies and take responsibility for their own studies. The self-directed models, either with or without intervention, are exactly what they need for taking control of their own studies. When they can set their own learning objectives, choose how to achieve them and assess themselves, learners will be inherently interested in study and thus improve their motivation to learn and language output. The self-directed models, with or without intervention, are better than the traditional model in encouraging the self-directed learning behaviors of students, which demonstrates that they do help students improve their self-directed learning behaviors. However, the self-directed learning model without intervention is less productive than the one with intervention. We found in the interview that quite a few students liked assess their own studies based on extrinsic feedback. It indicates that the self-directed learning model requires both external and internal support, as well as a higher sense of autonomy and better self-management ability from the part of students. To improve the self-directed learning ability of learners, it requires more than the provision of self-directed learning opportunities. Their ideas, attitudes and learning ability can also make a difference in the outcome.

\section{CONCLUSION}

The results and findings in this paper will be conductive to make both the teachers and students realize the importance of in the process of language learning. We applied qualitative and quantitative analysis in the article and surveyed and studied the motivation, metacognition and self-directed learning behaviors of college students learning a foreign language in self-directed learning and traditional models for a year. The findings are as follows: 1) the motivation, metacognition and self-directed learning behaviors of language students are subject to the environment and their backgrounds; 2) the target value and causal attribution, the two factors related to motivation, and metacognition are closely correlated with self-directed learning behaviors; 3 ) resource-based and self-directed learning models can help students improve their self-directed learning behaviors, but the provision of learning resources alone is not enough to improve their self-directed learning ability and outcomes as intervention is also necessary. Therefore, we can never overlook the role of teachers while advocating self-directed learning. Self-directed learning means more than the provision of a corresponding environment or real-life language materials, nor does it mean that students should take on the responsibility alone for making study plans, scheduling their tasks or monitoring and assessing their results. The appropriate and effective intervention by teachers is essential and necessary to the transformation of the self-directed learning prospect of their students into a reality, as well as a vital premise for ensuring and improving their self-directed learning ability.

\section{REFERENCES}

[1] Bialystock, E. The Role of Conscious Strategies in Second Language Proficiency [J]. Modern. Language journal 65, 1981: 24-35.

[2] O’Malley, J. M. \& Chamot A.U. etc. Learning Strategy Applications with Students of English as a Second Language. [J]. TESOL Quarterly 19, 1985(3):557-584.

[3] Oxford, R. L. Language Learning Strategies: What every teacher should know [M].New York: Newbury House/Harper \& Row, 1990. 
[4] Oxford, R. L., \& Nyikos, M. Variables Affecting Choice of Language Learning Strategies by University Students [J]. The Modern Language Journal 73, 1989: 291-300.

[5] Weijie Zhou, A Comparison of Language Learning Strategies between ESL and Chinese Students [J]. Sino-Us English Teaching ISSN1539-8072, USA Dec.2004, Volume 1NO.12, 2004.
[6] Zhenhui Rao. A Close Look at the Chinese Cultural Influence on Students' Learning Styles and Strategies [J].Asian Englishes Vol. 5, 2002 (1): 41-63. 